\title{
IDENTIFICATION OF DELAMINATION IN COMPOSITE BEAMS USING THE FRACTAL DIMENSION-BASED DAMAGE IDENTIFICATION ALGORITHM
}

\author{
Andrzej Katunin, Michał Zuba \\ Institute of Fundamentals of Machinery Design, Silesian University \\ of Technology, Konarskiego 18A, 44-100 Gliwice, Poland
}

\begin{abstract}
Damage detection and identification is one of the most important tasks of proper operation of technical objects and structures. It is, therefore, essential to develop efficient and sensitive methods of early damage detection. Delamination is the type of damage occurring in laminated composites that is one of the most dangerous and most difficult to detect. In this paper, the computational study was performed on the numerical data of the modal shapes of laminated composite beams with simulated delaminations in order to detect them using a fractal dimension-based approach. The obtained results allowed for improvement of detection accuracy as compared to previously applied wavelet-based approach. An additional benefit was decreasing the computational time. Basing on the obtained results it is reasonable to consider the presented approach as a promising alternative to currently applied signal processing methods used for supporting nondestructive testing of structures.
\end{abstract}

Keywords: structural damage identification, fractal dimension, non-destructive testing, composite structures, delamination.

\section{INTRODUCTION}

A growing demand for structural elements made of composite materials in various industrial disciplines makes the structural diagnosis during operational lifetime increasingly important. In composite materials, due to their high anisotropy, the initiation of damage is characterised by complex fracture mechanisms. At the same time, high material anisotropy makes damage difficult to detect and identify. Having said that, it is important to remember that the early damage detection is crucial for planning repairs of composite elements or their replacement in order to prevent catastrophic failure. To conclude, appropriate diagnostic methods that would allow detecting and identifying structural damage in the earliest possible stage of its propagation should be developed. 
From a variety of non-destructive testing (NDT) methods one of the oldest, but still effective and intensively developed approach is the vibration-based structural damage identification (SDI). This approach involves estimation of structural parameters for SDI, namely, natural frequencies of vibration, modal shapes and structural damping. Although changes in natural frequencies can be a simple indicator of a structural damage and many methods of damage identification based on changes in natural frequencies were developed in the $80 \mathrm{~s}$. of the $20^{\text {th }}$ century [1-3], this approach seems to be ineffective in the case of small structural damage. Moreover, considering variable properties of composite structures, changes in natural frequencies, which represent the global structural characteristic, are unreliable. In contrast, the SDI methods based on analysis of modal shapes allow for local damage detection and identification, and a development of new methods in past two decades was based mainly on analysing of modal shapes or curvatures. Additionally, the analysis of modal shapes or curvatures allows resigning from a reference used for SDI, while in the analysis of natural frequencies requires the knowledge about the properties of a healthy structure. The identification of damage in the methods based on the analysis of modal curvatures uses changes in local structural stiffness caused by damage, since when the damage occurs, the stiffness in the damage location decreases.

One of the simplest vibration-based SDI methods is the estimation of modal shapes' derivatives (see e.g. [4,5]), which are sensitive enough to determine tiny changes in a structure made by damage. Since the estimation of modal shapes' derivatives does not ensure high sensitivity to small damage as well as contain additional artefacts that hinder the evaluation of the results, recent research in vibration-based SDI has been focused on increasing the effectiveness of early damage detection and identification. An effective approach being now developed is the wavelet analysis (WA) of modal shapes, characterized by very high sensitivity to even tiny damage [6-10]. However, the application of the wavelet transform (WT) has several drawbacks, namely, the result depends on the selected wavelet function and its parameters as well as on the selected wavelet transform. Additionally, the SDI algorithms based on WA are quite time-consuming, which limits their application to off-line post-processing only. Considering this, an algorithm which combines SDI effectiveness and rapidness and allows for its implementation on a hardware, is highly desirable.

A good candidate for such an algorithm is the method based on estimation of fractal dimension (FD). The FD analysis provides a fast computational tool to track a degree of signal's complexity. In contrast to WA the FD analysis does not require defining basic functions and operates on simple algebraic relations. 
This is why it finds wide applicability across a range of scientific disciplines. For example, the authors of [11] used FD for diagnosing a cavitating pump system based on pressure fluctuation and vibration signals, the authors of [12] used FD for detecting patterns in process data, while in [13] the authors applied the FD analysis for the evaluation of seismogenic emissions used for early earthquake detection. FD analysis also finds application in biomedical signal processing: Solhjoo et al. [14] used it for electro-encephalographic signal analysis while Mishra and Raghav [15] classified arrhythmia based on the FD analysis of electrocardiographic signals.

The FD approach also finds an application in solving SDI problems. The first investigation into possible applications of the FD for crack detection in beams was undertaken by Hadjileontiadis et al. [16], where the authors used FD of Katz's formulation. Further, various FD algorithms were applied for cracks identification in structures, in particular, Wang and Qiao [17] used generalized fractal dimension algorithm based on Katz's formulation for crack detection in simulated modal shapes of beams. A year after, the authors of [18] proposed several improvements to the original Katz's FD algorithm and successfully verified a proposed method experimentally on artificially cracked beams. The authors of $[19,20]$ proposed a curvature difference probability method of waveform fractal dimension and applied this method to crack localization in steel beams. The most recent studies were performed by the Polish-Chinese research group, where the authors proposed an approach of FD analysis of higher-order modal shapes [21], and an approach based on data fusion of FD features [22] used for crack localization in metallic beams. In the authors' group several studies in topics of damage identification using FD approach were performed. In [23] the author analyzed the effectiveness of damage identification using Higuchi FD formulation, while in [24] the authors analyzed and compared all available formulations of FD based on simulation data of modal shapes of cracked beam.

As it was mentioned before, four initial FD formulations were proposed to-date, namely, Katz's FD [25], Higuchi FD [26], Petrosian FD [27], and Sevcik FD [28]. According to the results of previous studies [23], the Higuchi FD algorithm was chosen for damage identification, since it preserves best resolution and stability, which is proven by comparative analyses of other authors $[29,30]$. Moreover, the comparative analysis performed for various FD formulations in the problem of structural damage identification [24] also shows good performance of the Higuchi FD algorithm.

In this paper, the authors intended to apply the FD approach for identification of delaminations in composite beams. Since delaminations are poorly detectable 
in general, and thus, give much lower vibrational response during the modal analysis of a structure, the problem is not trivial. The presented studies were performed on numerical models of delaminated composite beams and the effectiveness of detection and identification of delaminations was compared to previous studies on this data analyzed using WT [10], which is considered one of the most sensitive methods, and can be assumed here as a reference. The FDbased approach, in contrast to WT-based one, is much more computationally efficient, and is therefore, analyzed in this paper.

\section{FRACTAL DIMENSION ALGORITHM}

According to the results of comparative analyses described above, the Higuchi FD algorithm was chosen for this study. Higuchi FD is determined in two steps [26]. Firstly, $k$ new series $X_{m}^{k}$ are constructed from the given displacements series $X_{n}$ of a modal shape with a discrete regular interval $k$ :

$$
X_{m}^{k}=\left\{x(m), x(m+k), x(m+2 k), \ldots, x\left(m+\operatorname{int}\left(\frac{N-m}{k}\right)\right)\right\}
$$

where $n=1, N$ denotes the number of measurement points, $m=1, k$ is the initial value. Then, the length $L(m, k)$ of the series $X_{m}^{k}$ is calculated for each of $k$ series:

$$
L(m, k)=\frac{1}{k}\left\{\frac{N-1}{k \operatorname{int}\left(\frac{N-m}{k}\right)} \sum_{i=1}^{\operatorname{int}\left(\frac{N-m}{k}\right)}|X(k i+m)-X(k(i-1)+m)|\right\}
$$

The obtained values of $L(m, k)$ are averaged for all $m$ forming $k$ mean values of the curve lengths $L(k)$. Higuchi FD is estimated as a slope of the least squares linear regression of the ratio:

$$
D_{H}=\log (L(k)) / \log \left(k^{-1}\right)
$$




\section{PROCEDURE AND RESULTS OF THE IDENTIFICATION OF DELAMINATION}

\subsection{Data preparation}

The analysis of detection and localization of delaminations in 12-layered laminated composite beams was performed on the simulation data obtained from numerical modal analysis performed on numerical models with use of the finite element method. Four groups of cases were considered: delamination on the large area along the length and through-the-width of a beam (symbol ' 1 ') - Fig. 1a), delamination on the large area along the length and on the limited area along the width (symbol 'il') - Fig. 1b), and the same cases for the delaminations on the small area along the length (symbols 'sl' and 'isl') - Figs. 1c),d). Each of the considered groups of delaminations consisted of 11 cases: the delamination was modelled between all of the layers of a considered 12-layered laminate. The schemes of considered groups were presented in Fig. 1. For the details on the numerical model, the material's properties and calculations see [10].

a)

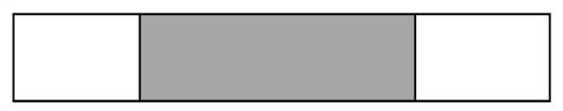

c)

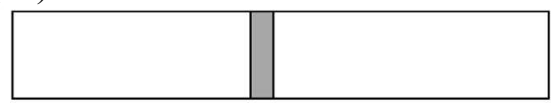

b)

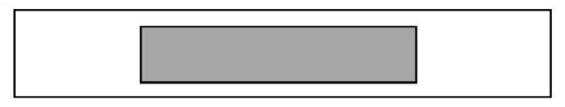

d)

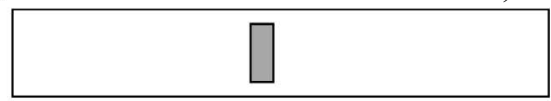

Fig. 1. Considered types of delaminated regions with locations [10].

The delaminations were modeled by deactivating the contact constraints in the selected regions. The locations of delaminations' boundaries in the considered cases were as follows: for the groups ' 1 ' and 'il': $x_{1}^{0}=85 \mathrm{~mm}$, $x_{2}^{0}=137 \mathrm{~mm}$ and for three groups 'sl' and 'isl': $x_{1}^{0}=95 \mathrm{~mm}, x_{2}^{0}=105 \mathrm{~mm}$. Second to fifth bending modal shapes were selected for further analysis. The displacements of these modal shapes were quantified along the length and in the half-width of the beams [10].

\subsection{Analysis of the results and comparative studies}

In order to evaluate the results of the performed delamination detection and localization in composite beams and to compare these results with the previously obtained ones using WT-based approach [10], the following measures need to be introduced: 


$$
\begin{gathered}
m_{\text {diff }}=\frac{1}{n} \sum_{i=1}^{n} \mathrm{abs}\left(\text { Diff }_{i}\right)=\frac{1}{n} \sum_{i=1}^{n} \mathrm{abs}\left[\left(x_{2}^{0}-x_{1}^{0}\right)-\left(x_{2}^{F D}-x_{1}^{F D}\right)\right] \\
m_{c d}=\frac{1}{n} \sum_{i=1}^{n} \mathrm{abs}\left(E r r_{i}\right)=\frac{1}{n} \sum_{i=1}^{n} \mathrm{abs}\left[\frac{1}{2}\left(x_{2}^{0}-x_{1}^{0}\right)-\frac{1}{2}\left(x_{2}^{F D}-x_{1}^{F D}\right)\right]_{i}
\end{gathered}
$$

where $m_{\text {diff }}$ describes the mean absolute value from the difference of real positions of the boundaries of the delamination $x_{1}^{0}$ and $x_{2}^{0}$, and the locations of the boundaries of a delamination detected by the Higuchi FD algorithm $x_{1}^{F D}$ and $x_{2}^{F D} ; m_{c d}$ describes in the same way the mean value of the deviation of geometric center of the real and detected delamination. The obtained results for the four considered groups of delaminations are presented in Table 1. In this table the data for the locations of delaminations between various layers with enumeration from the bottom of beams is presented, i.e. the case 1 denotes the delamination between the layers 1 and 2, the case 2 - between the layers 2 and 3 , etc. Note that due to the artifacts produced by the algorithm at the beginning of a signal, this part was not considered during evaluation of the defined measures. In order to visualize the results from each group two representative cases are selected, with badly and well detected delamination boundaries. They are presented in Fig. 2.

As can be seen in Table 1, in most cases the differences between the real delamination boundaries and those detected using the FD-based algorithm are small, which proves the overall effectiveness of the prosed approach. In the cases 'il' and 'isl' the resulting differences are bigger in comparison with their analogues, namely, ' 1 ' and 'sl'. This is because the magnitudes of vibrations in the region of boundaries of delaminations in the cases 'il' and 'isl' are much smaller than those in the cases ' 1 ' and 'sl', and thus, the influence of noise is higher.

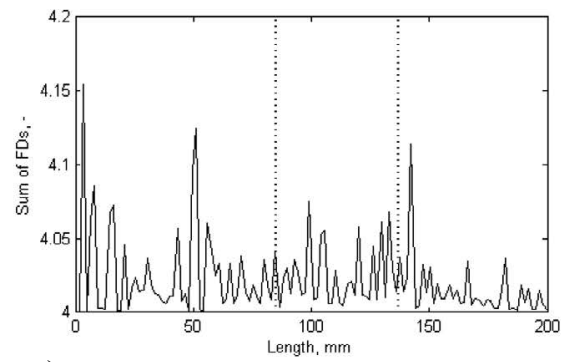

a)

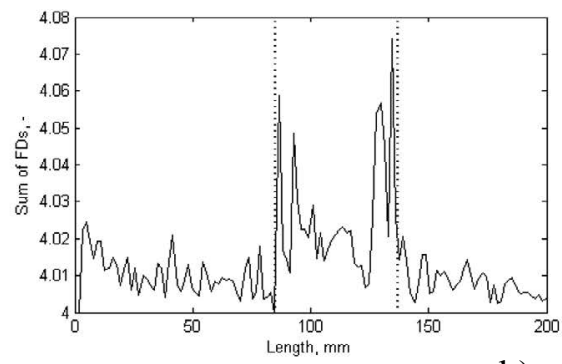

b) 


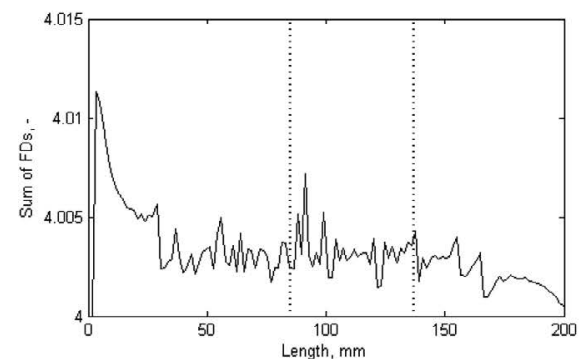

c)

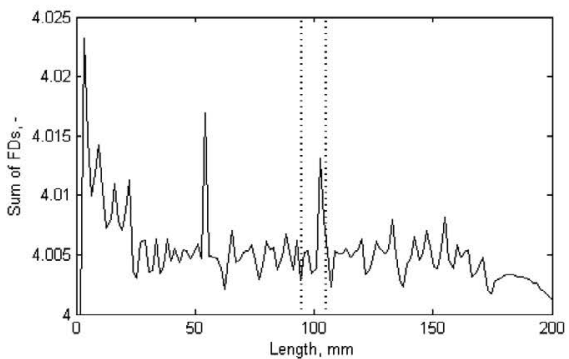

e)

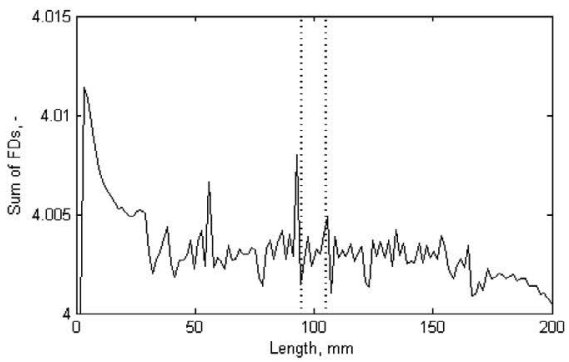

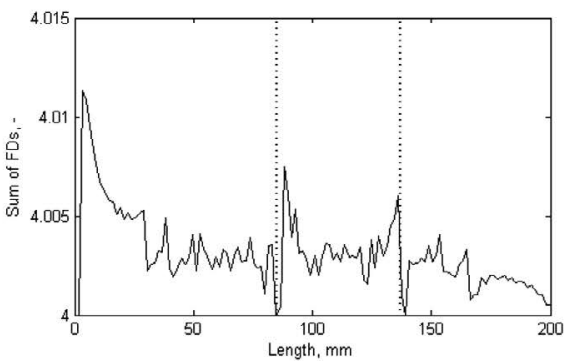

d)

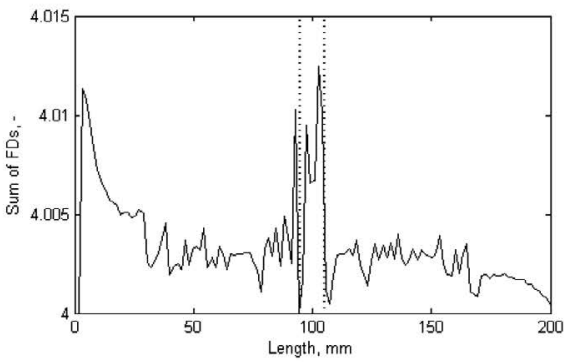

f)

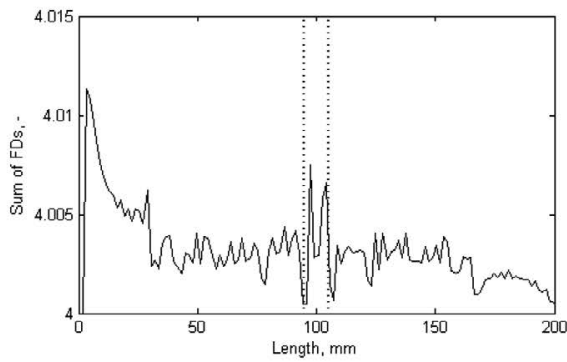

Fig. 2. Exemplary results of FD-based analysis, badly and well recognized delaminations for a),b) (-case, (),d) il-case, e),f) sl-case, and g),h) isl-case.

In order to evaluate the effectiveness of the proposed FD-based approach for delamination detection and identification it is suitable to compare the obtained results to the WT-based algorithm with optimization of wavelet parameters developed previously and described in [10]. Due to the advancement of the WTbased algorithm the results obtained using this algorithm can be considered as reference. For clarity, these results are presented in Table 2. 
Table 1. Measures of sensitivity obtained for the considered locations of delaminations using FD-based algorithm

\begin{tabular}{|c|c|c|c|c|c|c|c|c|}
\hline Symbol of a group & \multicolumn{2}{|c|}{ 'l' } & \multicolumn{2}{c|}{ 'il' } & \multicolumn{2}{c|}{ 'sl' } & \multicolumn{2}{c|}{ 'isl' } \\
\hline No. of a case & $\begin{array}{c}\mathbf{m}_{\text {diff' }} \\
\mathbf{m m}\end{array}$ & $\begin{array}{c}\mathbf{m}_{\text {cd' }}, \\
\mathbf{m m}\end{array}$ & $\begin{array}{c}\mathbf{m}_{\text {diff' }} \\
\mathbf{m m}\end{array}$ & $\begin{array}{c}\mathbf{m}_{\text {cd }}, \\
\mathbf{m m}\end{array}$ & $\begin{array}{c}\mathbf{m}_{\text {diff, }} \\
\mathbf{m m}\end{array}$ & $\begin{array}{c}\mathbf{m}_{\text {cd }}, \\
\mathbf{m m}\end{array}$ & $\begin{array}{c}\mathbf{m}_{\text {diff }} \\
\mathbf{m m}\end{array}$ & $\begin{array}{c}\mathbf{m}_{\mathrm{cd}} \\
\mathbf{m m}\end{array}$ \\
\hline 1 & 20,0 & 10,0 & 44,0 & 22,0 & 54,0 & 27,0 & 63,6 & 31,8 \\
\hline 2 & 0,8 & 0,4 & 7,2 & 3,6 & 38,0 & 19,0 & 26,8 & 13,4 \\
\hline 3 & 39,2 & 19,6 & 48,8 & 24,4 & 5,6 & 2,8 & 39,6 & 19,8 \\
\hline 4 & 0,8 & 0,4 & 40,8 & 20,4 & 5,2 & 2,6 & 2,0 & 1,0 \\
\hline 5 & 0,8 & 0,4 & 5,6 & 2,8 & 1,2 & 0,6 & 5,2 & 2,6 \\
\hline 6 & 39,2 & 19,6 & 5,6 & 2,8 & 5,2 & 2,6 & 36,4 & 18,2 \\
\hline 7 & 48,8 & 24,4 & 4,0 & 2,0 & 0,4 & 0,2 & 3,6 & 1,8 \\
\hline 8 & 4,0 & 2,0 & 4,0 & 2,0 & 5,2 & 2,6 & 5,2 & 2,6 \\
\hline 9 & 0,8 & 0,4 & 20,0 & 10,0 & 5,2 & 2,6 & 5,2 & 2,6 \\
\hline 10 & 37,6 & 18,8 & 15,2 & 7,6 & 3,6 & 1,8 & 5,2 & 2,6 \\
\hline 11 & 2,4 & 1,2 & 5,6 & 2,8 & 3,6 & 1,8 & 30,0 & 15,0 \\
\hline
\end{tabular}

Table 2. Measures of sensitivity obtained for the considered locations of delaminations using WT-based algorithm [10]

\begin{tabular}{|c|c|c|c|c|c|c|c|c|}
\hline Symbol of a group & \multicolumn{2}{|c|}{ 'l' } & \multicolumn{2}{c|}{ 'il' } & \multicolumn{2}{c|}{ 'sl' } & \multicolumn{2}{c|}{ 'isl' } \\
\hline No. of a case & $\begin{array}{c}\mathbf{m}_{\text {diff }} \\
\mathbf{m m}\end{array}$ & $\begin{array}{c}\mathbf{m}_{\text {cd' }}, \\
\mathbf{m m}\end{array}$ & $\begin{array}{c}\mathbf{m}_{\text {diff }} \\
\mathbf{m m}\end{array}$ & $\begin{array}{c}\mathbf{m}_{\mathbf{c d}}, \\
\mathbf{m m}\end{array}$ & $\begin{array}{c}\mathbf{m}_{\text {diff }} \\
\mathbf{m m}\end{array}$ & $\begin{array}{c}\mathbf{m}_{\text {cd }} \\
\mathbf{m m}\end{array}$ & $\begin{array}{c}\mathbf{m}_{\text {diff }} \\
\mathbf{m m}\end{array}$ & $\begin{array}{c}\mathbf{m}_{\text {cd' }} \\
\mathbf{m m}\end{array}$ \\
\hline 1 & 20,0 & 10,0 & 38,6 & 19,3 & 25,2 & 12,6 & 4,5 & 2,2 \\
\hline 2 & 21,5 & 10,7 & 23,5 & 11,7 & 25,7 & 12,9 & 20,0 & 10,0 \\
\hline 3 & 6,2 & 3,1 & 18,9 & 9,5 & 26,2 & 13,1 & 30,6 & 15,3 \\
\hline 4 & 23,1 & 11,5 & 18,1 & 9,0 & 24,9 & 12,4 & 30,5 & 15,2 \\
\hline 5 & 27,7 & 11,8 & 29,7 & 14,9 & 23,2 & 11,6 & 32,2 & 16,1 \\
\hline 6 & 19,3 & 9,7 & 31,5 & 15,8 & 27,4 & 13,7 & 33,4 & 16,7 \\
\hline 7 & 18,8 & 9,4 & 24,7 & 12,3 & 26,1 & 13,0 & 31,4 & 15,7 \\
\hline 8 & 17,5 & 8,7 & 28,8 & 14,4 & 24,1 & 12,0 & 35,4 & 17,7 \\
\hline 9 & 18,9 & 9,4 & 12,4 & 6,2 & 25,7 & 12,9 & 36,1 & 18,1 \\
\hline 10 & 29,5 & 14,8 & 16,3 & 8,1 & 26,6 & 13,3 & 38,1 & 19,0 \\
\hline 11 & 19,1 & 9,5 & 13,6 & 6,8 & 30,1 & 15,0 & 31,1 & 15,5 \\
\hline
\end{tabular}


The difference values between the results obtained using FD- and WT-based algorithms were determined for all considered cases and presented in Table 3. The positive values of these differences denote improvement of the identification accuracy of FD-based approach with respect to the WT-based one, while the negative values indicate the worst results with respect to previously applied WT-based approach.

Based on the results presented in Table 3, it can be observed that the most of the presented values are positive, which point on the better effectiveness of the proposed FD-based algorithm in detection of boundaries of delaminations in various configurations. This improvement is especially observable for smallarea delaminations (cases 'sl' and 'isl').

Table 3. Differences in the obtained results using FD- and WT-based algorithms

\begin{tabular}{|c|c|c|c|c|c|c|c|c|}
\hline $\begin{array}{c}\text { Symbol } \\
\text { of a group }\end{array}$ & \multicolumn{2}{|c|}{ 'l' } & \multicolumn{2}{|c|}{ 'il' } & \multicolumn{2}{c|}{ 'sl' } & \multicolumn{2}{c|}{ 'isl' } \\
\hline No. of a case & $\begin{array}{c}\mathbf{m}_{\text {diff }} \\
\mathbf{m m}\end{array}$ & $\begin{array}{c}\mathbf{m}_{\mathrm{cd}}, \\
\mathbf{m m}\end{array}$ & $\begin{array}{c}\mathbf{m}_{\text {diff' }} \\
\mathbf{m m}\end{array}$ & $\begin{array}{c}\mathbf{m}_{\mathrm{cd}}, \\
\mathbf{m m}\end{array}$ & $\begin{array}{c}\mathbf{m}_{\text {diff }} \\
\mathbf{m m}\end{array}$ & $\begin{array}{c}\mathbf{m}_{\mathrm{cd}}, \\
\mathbf{m m}\end{array}$ & $\begin{array}{c}\mathbf{m}_{\text {diff }} \\
\mathbf{m m}\end{array}$ & $\begin{array}{c}\mathbf{m}_{\mathrm{cd}} \\
\mathbf{m m}\end{array}$ \\
\hline 1 & 0,0 & 0,0 & $-5,4$ & $-2,7$ & $-28,8$ & $-14,4$ & $-59,1$ & $-29,6$ \\
\hline 2 & 20,7 & 10,3 & 16,3 & 8,1 & $-12,3$ & $-6,1$ & $-6,8$ & $-3,4$ \\
\hline 3 & $-33,0$ & $-16,5$ & $-29,9$ & $-14,9$ & 20,6 & 10,3 & $-9,0$ & $-4,5$ \\
\hline 4 & 22,3 & 11,1 & $-22,7$ & $-11,4$ & 19,7 & 9,8 & 28,5 & 14,2 \\
\hline 5 & 26,9 & 11,4 & 24,1 & 12,1 & 22,0 & 11,0 & 27,0 & 13,5 \\
\hline 6 & $-19,9$ & $-9,9$ & 25,9 & 13,0 & 22,2 & 11,1 & $-3,0$ & $-1,5$ \\
\hline 7 & $-30,0$ & $-15,0$ & 20,7 & 10,3 & 25,7 & 12,8 & 27,8 & 13,9 \\
\hline 8 & 13,5 & 6,7 & 24,8 & 12,4 & 18,9 & 9,4 & 30,2 & 15,1 \\
\hline 9 & 18,1 & 9,0 & $-7,6$ & $-3,8$ & 20,5 & 10,3 & 30,9 & 15,5 \\
\hline 10 & $-8,1$ & $-4,0$ & 1,1 & 0,5 & 23,0 & 11,5 & 32,9 & 16,4 \\
\hline 11 & 16,7 & 8,3 & 8,0 & 4,0 & 26,5 & 13,2 & 1,1 & 0,5 \\
\hline
\end{tabular}

\section{CONCLUSIONS}

The paper presents results of analysis of the effectiveness of fractal dimension-based computational approach applied for delamination detection and identification based on processing of vibrational modal shapes of delaminated composite beams. The results of the presented numerical study shows a potential of application of such an approach in diagnostic signal processing, and revealed 
better quantitative results in comparison with previously analysed WT-based approach. Additionally, the presented approach benefits in much shorter computational time with respect to the WT-based approach, and thus, can be easily implemented in real-time monitoring systems.

\section{REFERENCES}

[1] West W.M., Illustration of the use of modal assurance criterion to detect structural changes in an orbiter test specimen, Proceedings of the Air Force Conference on Aircraft Structural Integrity, 1-6, 1984.

[2] Leiven N.A.J., Ewins D.J., Spatial correlation of mode shapes, the Coordinate Modal Assurance Criterion (COMAC), Proceedings of the Sixth International Modal Analysis Conference, 1, 690-695, 1988.

[3] Shi Z.Y., Law S.S., Zhang L.M., Damage localization by directly using incomplete mode shapes, Journal of Engineering Mechanics, 126(6), 656-660, 2000.

[4] Ismail Z., Abdul Razak H., Abdul Rahman A.G., Determination of damage location in RC beams using mode shape derivatives, Engineering Structures,28(11), 1566-1573, 2006.

[5] Whalen T.M., The behavior of higher order mode shape derivatives in damaged, beam-like structures, Journal of Sound and Vibration,309(3-5), 426-464, 2008.

[6] Douka E., Loutridis S., Trochidis A., Crack identification in beams using wavelet analysis, International Journal of Solids and Structures, 40(13-14), 3557-3569, 2003.

[7] Rucka M., Wilde K., Application of continuous wavelet transform in vibration based damage detection method for beams and plates, Journal of Sound and Vibration, 297(3-5), 536-550, 2006.

[8] Zhong S., Oyadiji S.O., Crack detection in simply supported beams without baseline modal parameters by stationary wavelet transform, Mechanical Systems and Signal Processing, 21(4), 1853-1884, 2007.

[9] Katunin A., Holewik F., Crack identification in composite elements with non-linear geometry using spatial wavelet transform, Archives of Civil and Mechanical Engineering, 13(3), 287-296, 2013.

[10] Katunin A., Przystałka P., Detection and localization of delaminations in composite beams using fractional B-spline wavelets with optimized parameters, Eksploatacja i Niezowodnosc - Maintenance and Reliability,15(3), 391-399, 2014.

[11] Simard P., le Tavernier E., Fractal approach for signal processing and application to the diagnosis of cavitation, Mechanical Systems and Signal Processing, 14(3), 459-469, 2000.

[12] Purintrapiban U., Kachitvichyanukul V., Detecting patterns in process data with fractal dimension, Computers \& Industrial Engineering,45(4), 653-667, 2003. 
[13] Gotoh K., Hayakawa M., Smirnova N.A., Hattori K., Fractal analysis of seismogenic ULF emissions, Physics and Chemistry of the Earth, 29(4-9), 419-424, 2004.

[14] Solhjoo S., Nasrabadi A.M., Golpayegani M.R.H., EEG-based mental task classification in hypnotized and normal subjects, Proceedings of the 2005 IEEE Engineering in Medicine and Biology 27th Annual Conference, Shanghai, 2041-2043, 2005.

[15] Mishra A.K., Raghav S., Local fractal dimension based ECG arrhythmia classification, Biomedical Signal Processing and Control, 5(2), 114-123, 2010.

[16] Hadjileontiadis L.J., Douka E., Trochidis A., Fractal dimension analysis for crack identification in beam structures, Mechanical Systems and Signal Processing, 19(3), 659-674, 2005.

[17] Wang J., Qiao P., Improved damage detection for beam-type structures using a uniform load surface, Structural Health Monitoring, 6(2), 99-110, 2007.

[18] Qiao P., Cao M., Waveform fractal dimension for mode shape-based damage identification of beam-type structures, International Journal of Solids and Structures, 45(22-23), 5946-5961, 2008.

[19] Li H., Huang Y., Ou J., Bao Y., Fractal dimension-based damage detection method for beams with a uniform cross-section, Computer-Aided Civil and Infrastructure Engineering, 26, 190-206, 2011.

[20] An Y., Ou J., Experimental and numerical studies on damage localization of simply supported beams based on curvature difference probability method of waveform fractal dimension, Journal of Intelligent Material Systems and Structures, 23(4), 415-426, 2011.

[21] Bai R., Cao M., Su Z., Ostachowicz W., Xu H., Fractal dimension analysis of higher-order mode shapes for damage identification of beam structures, Mathematical Problems in Engineering, 2012, ID 454568, 2012.

[22] Bai R.B., Song X.G., Radzieński M., Cao M.S., Ostachowicz W., Wang S.S., Crack location in beams by data fusion of fractal dimension features of laser-measured operating deflection shapes, Smart Structures and Systems, 13(6), 975-991, 2014.

[23] Katunin A., Fractal dimension-based crack identification technique of composite beams for on-line SHM systems, Machine Dynamics Research, 34(2), 60-69, 2010.

[24] Katunin A., Serzysko K., Detection and localization of cracks in composite beams using fractal dimension-based algorithms - a comparative study, Machine Dynamics Research 38(2), 27-36, 2014.

[25] Katz M., Fractals and the analysis of waveforms, Computers in Biology and Medicine, 18, 145-156, 1988.

[26] Higuchi T., Approach to an irregular time series on the basis of the fractal theory, Physica D, 31, 277-283, 1988. 
[27] Petrosian A., Kolmogorov complexity of finite sequences and recognition of different preictal EEG patterns, Proceedings of IEEE Symposium on ComputerBased Medical Systems, 212-217, 1995.

[28] Sevcik C., On fractal dimension of waveforms, Chaos Solitons and Fractals, 28, 579-580, 2006.

[29] Esteller R., Vachtsevanos G., Echauz J., Litt B., A comparison of fractal dimension algorithms using synthetic and experimental data, Proceedings of the 1999 IEEE International Symposium of Circuits and Systems, 3, 199-202, 1999.

[30] Raghavendra B.S., Dutt D.N., Computing fractal dimension of signals using multiresolution box-counting method, International Journal of Engineering and Mathematical Sciences, 6, 53-68, 2010. 